\title{
Italian Early Adolescent Females' Intrinsic Motivation in Sport: An Explorative Study of Psychological and Sociorelational Correlates
}

Authors' contribution:

A) conception and design of the study

B) acquisition of data

C) analysis and interpretation of data

D) manuscript preparation

E) obtaining funding
Giulia Zucchetti ${ }^{1 \text { A-E }}$, Filippo Candela ${ }^{1 \text { A-E }}$, Emanuela Rabaglietti ${ }^{1 \text { A-E }}$, Alessandra Marzari ${ }^{2}$ A-E

${ }^{1}$ University of Torino, Italy

${ }^{2}$ Vero Volley Society, Monza, Italy

KEYWORDS

\begin{abstract}
Using self-determination theory (SDT), this study simultaneously investigated the relationships between intrinsic motivation, psychological factors (sport enjoyment, social self-efficacy), and sociorelational factors (perceived coaching behaviors) by subsequently testing whether psychological factors mediate the relationships between social-relational factors and intrinsic motivation. One hundred and twentyseven early adolescent females from several teams of the Italian Volleyball Society completed a self-report questionnaire. Results showed that female athletes' intrinsic motivation was associated with a) sport enjoyment and b) perceived coaching behaviors (e.g., training and instruction, social support). Second, results showed that training-and-instruction coaches' leadership style affected intrinsic motivation via the females' enjoyment in sport. This study provided further insights into unknown associations among psychological, sociorelational factors and intrinsic motivation, highlighting the innovative role of sport enjoyment as a key factor for sustaining intrinsic motivation. Original and useful behavioral suggestions will be given to the coaches in order to sustain female athletes' sport enjoyment and their intrinsic motivation.

enjoyment, coaching behavior, females, intrinsic motivation
\end{abstract}

\section{Introduction}

Previous work has shown that there is a decline in participation in physical activity among youths over their teenage years, especially among females (Sallis, Prochaska, Taylor, 2000; Vescio, Wilde, Crosswhite, 2005). In Italy, the situation has been changing and the percentage of young people who practice sport has increased in the last years (53\% vs. 59\%, Italian National Olympic Committee, 2011). However, remarkable gender differences exist, indicating that during early adolescence, females are more inactive and sedentary and practice sporting activities less often than males (National Institute of Statistics, 2012). These gender differences lead females to experience greater risk for health disease (e.g., obesity) and for their general development (Fraser-Thomas, Cote, Deakin, 2005). For these reasons, recent research has concentrated on the study of motivational determinants associated with youths' sport engagement, especially among females. 
This line of research is extremely relevant as investigating sport motivation may have important practical implications for reducing females' early sport dropout (McDonough \& Crocker, 2005; Pelletier, Fortier, Vallerand, \& Briere, 2001; Ulrich-French \& Smith, 2009).

According to the self-determination theory (SDT; Deci \& Ryan, 1985; Ryan \& Deci, 2000), individual behaviors can be categorized as intrinsically motivated, extrinsically motivated, or amotivated: This distinction is based on the different reasons that give rise to daily action. Intrinsic motivation, which refers to motivation that comes from the individual's inner reasons (e.g., interest) rather than from any external rewards (e.g., trophies), is the most self-determined type of motivation identified by SDT, and it is probably one of the main components of a positive and successful sport experience (Duda, 2007; Vallerand, 2007). This type of motivation allows everyone to experience a positive and exciting sporting context that provides, in turn, opportunities to participate in challenging activities (Vallerand, 1997). Furthermore, it is highly probable that athletes with an intrinsic motivation will persist in their sporting experiences (Ntoumanis, 2005; Sarrazin, Vallerand, Guillet, Pelletier, Cury, 2002), accepting the challenges of these activities. Along these benefits of engaging in activities for intrinsic reasons, much research has concentrated on identifying the factors that enhance intrinsic motivation. Overall, previous work has demonstrated that there are both psychological and sociorelational factors that are able to influence and promote intrinsic motivation for sport in different ways (e.g., Ferrer-Caja \& Weiss, 2000; Hollembeak \& Amorose, 2005; Ntoumanis, 2001; Reinboth \& Duda, 2006). Nonetheless, some relevant questions remain open.

First, among psychological aspects, the role of social self-efficacy and sport enjoyment in intrinsic motivation remains unclear. Although some researchers (Bandura, 1997; Deci \& Ryan, 1985, 1991; Vallerand, 1997, 2007) have recognized that self-efficacy, which refers to an individual's judgments about his or her abilities in a particular area (e.g., physical activity, peer relationships) is related to intrinsic motivation, few studies, to our knowledge, have examined the possible contribution of social self-efficacy to the level of intrinsic motivation (Klint \& Weiss, 1987). Social self-efficacy relates to individuals' judgments about their ability in social relationships in different contexts, such as in school or in sports teams (Bandura, 1997). In the current study, it is assumed that beliefs of one's own social efficacy are significant for early adolescent females and can contribute to an increase in their intrinsic sport motivation. In fact, many studies have demonstrated that the social interactions with friends on sport teams are associated with the quality of sport experience and the level of sport engagement (Duncan, 1993; Weiss, Smith, \& Theehoom, 1996; Wylleman, 2000). Sport enjoyment instead, considered here as the positive affect associated with involvement in physical activities, has generally been discussed with regard to intrinsic motivation (FerrerCaja \& Weiss, 2000; Ryan \& Deci, 2000). Nonetheless, the major portion of SDT research (Deci \& Ryan, 1985; Ryan \& Deci, 2000) has studied enjoyment as a measure of intrinsic motivation instead of a personal positive emotional attitude toward sport practice. As providing enjoyable sport experiences is an effective strategy for increasing activity levels in youths (Duda, 2007; Weiss, Kimmel, \& Smith, 2001), the present study investigated the direct contribution of sport enjoyment to intrinsic motivation.

Second, considering the sociorelational aspects, coaching leadership style is one of the factors associated with sport motivation within the SDT. Some researchers have underlined that specific coaches' styles (e.g., democratic style, positive feedback) are able to influence youths' sport motivation and to create a positive team climate (Amorose \& Anderson-Butcher, 2007; Amorose \& Horn, 2000; Hollembeak \& Amorose, 2005; Reinboth \& Duda, 2006; Sarrazin et al., 2002). To our knowledge, however, few studies (Amorose \& Horn, 2000; Hollembeak \& Amorose, 2007) have taken into account all the possible coaching styles suggested by the multidimensional styles (autocratic behavior, training and instruction, democratic behavior, social support, and positive feedback) of sport leadership given by Chelledurai and Saleh (1980) on the level of intrinsic motivation. Considering these styles could be useful to bring out those more related to the intrinsic motivation of Italian females, a group at risk of early sport dropout, in order to highlight the factors that sustain their sport engagement.

Third, the dynamics among psychological, sociorelational factors and intrinsic motivation remain unclear. Considering the relationship between coaching behavior and intrinsic motivation, few studies have 
specifically tested the extent to which alternative psychological factors, such as social self-efficacy and sport enjoyment, actually could mediate the above-mentioned relationship. Summarizing, the present study replicated and expanded this field of research by testing a model of simultaneous associations in order to investigate the contribution of some less-explored factors on intrinsic motivation simultaneously. On the basis of the above-mentioned literature, several hypotheses were tested: a) sport enjoyment will be positively associated with intrinsic motivation; b) perceived social self-efficacy will be positively associated with intrinsic motivation; and c) coaching leadership style will be directly associated with intrinsic motivation.

More specifically, as some studies have already shown, training and instruction, democratic behavior, social support, and positive feedback are positive behavior styles that the coach should adopt in specific sport situations with athletes in order to increase their long-term sport involvement, sport engagement, and intrinsic motivation (e.g., Amorose \& Horn, 2000; Pelletier et al., 2001). It was also assumed that autocratic behavior would be negatively associated with intrinsic motivation, as shown by Hollembeak and Amorose (2005). Subsequently, on the basis of the psychological and sociorelational variables associated with the intrinsic motivation, the dynamics between intrinsic motivation and the psychological and social-relational factors significantly associated with it will be clarified. Following the assumption of Vallerand's (1997, 2007) motivational sequence model in which the social-relational factors influence intrinsic motivation through the mediation of psychological aspects (perceived competence, autonomy, and relatedness), the study extended the above-mentioned model, taking into account some alternative psychological factors, such as enjoyment and social self-efficacy. Specifically, it was assumed that the coaching behaviors can contribute to the females' level of intrinsic motivation, satisfying their psychological needs of self-efficacy and enjoyment.

\section{Methods}

The current research was entirely submitted to and evaluated by the Bioethical Committee of the University of Torino, composed of different professionals (e.g., psychologists, psychiatrists, law experts). The members of the committee approved the methodology and the protocol of the research.

\section{Participants}

The main eight volleyball sport societies around the Lombard region in northwest Italy were involved in the study. A total of 200 female athletes participated in these teams, and the parents of 127 players gave the informal consent for their participation (64\% participant rate). The participants ranged in age from 10 to 14 years $(M$ age $=12.08$ years; $s=.97)$. The group of participants is representative of the population of early adolescents from this part of Italy; $98 \%$ of early adolescents attend a normal primary school. Also, regarding relevant structural indicators such as the proportion of divorces and the parents' level of education, our participants appeared relatively comparable to the general Italian population (National Institute of Statistics, 2011). Post hoc power analysis conducted with G-Power 3.1.5 software revealed that our sample was powerful enough to conduct our analysis without a high error probability (Power $(1-\beta$ err prob $)=.99)$.

\section{Measures}

Intrinsic motivation. Intrinsic motivation was assessed using the Sport Motivation Scale (SMS), validated by Pelletier, Fortier, Vallerand, Tuson, Briere, and Blais (1995). The instrument was administered in Italian. The instrument was originally written in French, translated into Italian, and then back-translated into French. French-speaking judges verified the semantic similarity between the back-translated items and the original items. In this questionnaire, athletes were asked the following question: "Why do you practice your sport?" Each item represents a perceived reason for engaging in the activity, thereby reflecting the various types of motivations. Items were assessed using a 7-point Likert-type scale with response choices ranging from Does not correspond at all to Corresponding exactly. There were four items per subscales and 
seven subscale items (intrinsic motivation knowledge, intrinsic motivation accomplishment, intrinsic motivation stimulation, identified regulation, introjected regulation, external regulation, and amotivation). The item responses of each scale of intrinsic motivation were summarized, and the total was used as the entire score of intrinsic motivation. The Cronbach alpha of the three scales was .86. Studies (for a review, see Pelletier, Vallerand, \& Sarrazin, 2007) confirmed the factor structure of the original scale and revealed a satisfactory level of internal consistency as well as adequate test-retest reliability.

Enjoyment. The Physical Activity Enjoyment Scale (PACES) by Kendzierski and DeCarlo (1991), translated into Italian by Carraro, Young, and Robazza (2008), was used to measure the participants' enjoyment in physical activity. The scale represents a valid measure of enjoyment of physical activity, and the factorial validity of its scores was evaluated in the sample of adolescent females. This scale was formed by 16 items, preceded by the phrase "When I am active ...," which directly assessed enjoyment (e.g., "When I am active I enjoy it", "it is very exciting") and the converse (e.g., "I feel bored", "I dislike it"). The responses were assessed on a Likert-type scale with score ranges fluctuating between 1 (Totally disagree) to 5 (Totally agree). The alpha value was .86.

Social self-efficacy. To measure social self-efficacy, the Self-Efficacy Social Perceived Scale (ASP) was used (Caprara, 2001). This scale consists of 12 items (Cronbach $\alpha=.85$ ) reflecting the ability of athletes to participate in a sports team, the ability to belong to a sports team, and the ability to build and maintain friendships on the team. The participants were asked to answer, keeping in mind their own sports team. The responses were collected on a 4-point Likert Scale with response choices ranging from Not at all to Very much.

Coaching behavior. The Leadership Scale for Sports (LSS), which was developed by Chelledurai and Saleh (1980), was used to measure different types of leadership behaviors. The LSS is composed of five subscales: democratic style, autocratic style, social support, positive feedback, and training and instruction. The democratic style describes a coach whose leadership style encourages participation from athletes in decisions, practice methods, and tactics (e.g., "Asks for the opinion of the athletes on strategies for specific competitions"). The autocratic style describes a coach whose leadership style stresses an athlete's own personal authority (e.g., "Works relatively independent of the athletes"). Social support describes a coach who establishes interpersonal relationships with the athletes (e.g., "Helps the athletes with their personal problems"). Positive feedback describes a coach who frequently reinforces athletes' performance (e.g., "Gives credit when credit is due"). Training and instruction describes a coach whose leadership style is characterized by an emphasis on training and instructing athletes (e.g., "Sees to it that every athlete is working to his/her capacity"). There are 40 total items scored on a 5-point scale from Always to Never. For each item, the athlete is asked to indicate the degree to which her own coach exhibits that particular type of behavior. The scale obtained an alpha value of .92 .

\section{Procedure}

Participant recruitment occurred through initial contact with coaches, sport leaders, and parents through a formal informational letter. The purpose and the procedures were explained during a face-to-face meeting. Parents provided written consent for the athletes (because they were minors) to participate in accordance with Italian law and the ethical code of the Professional Psychologists Association in Italy. Athletes completed the questionnaires, which were distributed by trained research staff during volleyball training. The questionnaires took approximately one hour to complete. Coaches were not present during the questionnaire administration. No incentives were offered for participation.

\section{Analysis}

First, a correlation analysis to determine relationships among variables was performed. Then, a multiple regression model connecting the intrinsic motivation score (dependent variable) to enjoyment, 
social self-efficacy, and coaching behaviors (independent variables) was conducted. In a second step, based on the variables significantly related to intrinsic motivation, a mediation analysis was performed with intrinsic motivation as the dependent variable, coaching behavior variables as independent variables, and psychological variables as mediators, according to Baron and Kenny's (1986) method. Linear regression analyses were used to assess mediation. All the analyses were performed using M-plus software version 6.0.

\section{Results}

Table 1 displays the correlation analysis of all the variables considered in the study. All the correlation variables had positive directions, except the autocratic style, which showed a negative correlation with intrinsic motivation. All the variables were included in the model to account for their contributions.

Table 1. Inter-Correlations Among and Descriptive Information of Intrinsic Motivation, Sport Enjoyment, Social SelfEfficacy, and Coaches' Leadership Style

\begin{tabular}{lllllllll}
\hline $\mathrm{n}=127$ & \multicolumn{1}{c}{1} & \multicolumn{1}{c}{2} & \multicolumn{1}{c}{3} & \multicolumn{1}{c}{4} & 5 & \multicolumn{1}{c}{5} & \multicolumn{1}{c}{7} \\
\hline 1. Intrinsic motivation & - & $.41^{* *}$ & $.30^{* *}$ & $.41^{* *}$ & $.35^{* *}$ & -.14 & $.31^{* *}$ & $.25^{* *}$ \\
2. Enjoyment & $.41^{* *}$ & - & .17 & $.30^{* *}$ & .16 & -.08 & .18 & .063 \\
3. Social self-efficacy & $.30^{* *}$ & .17 & - & $.38^{* *}$ & $.23^{*}$ & -.11 & $.19^{*}$ & $.37^{* *}$ \\
4. Training and instruction & $.41^{* *}$ & $.29 * *$ & $.38^{* *}$ & - & $.30^{* *}$ & -.17 & .15 & .14 \\
5. Democratic style & $.35^{* *}$ & .16 & $.23^{*}$ & $.30^{* *}$ & - & -.15 & $.33^{* *}$ & $.32^{* *}$ \\
6. Autocratic style & $-.14^{*}$ & -.084 & -.11 & -.17 & -.15 & - & -.01 & -.06 \\
7. Social support & $.31^{* *}$ & .18 & $.20^{*}$ & .15 & $.32^{* *}$ & -.01 & - & .17 \\
8. Positive feedback & $.25^{* *}$ & .06 & $.37^{* *}$ & .14 & $.32^{* *}$ & -.06 & .17 & 1 \\
$M(\mathrm{~N})$ & 47.50 & 48.09 & 42.6 & 52.78 & 23.78 & 9.86 & 20.6 & 16.55 \\
$S D(\%)$ & 6.58 & 3.58 & 4.76 & 7.4 & 6.56 & 3.56 & 6.15 & 3.94
\end{tabular}

Note: Significant correlations among intrinsic motivation, enjoyment, social self-efficacy, training and instruction, democratic style, social support, and positive feedback. Negative correlation among intrinsic motivation and autocratic style. $* \mathrm{p}<.05 ; * * \mathrm{p}<.01$.

Source: own study.

Next, the multiple regression model including all the variables was conducted. Figure 1 shows the results of the original model with standardized coefficients.

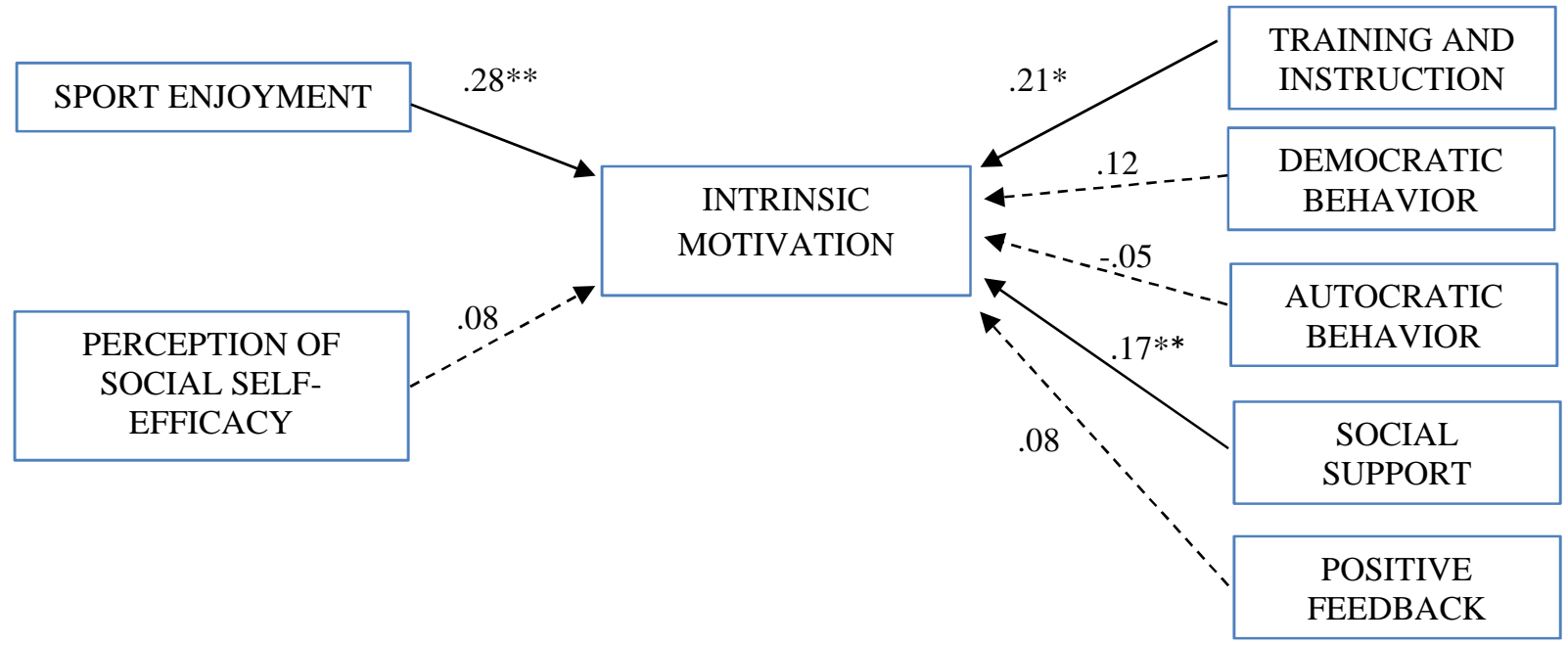

Figure 1. Standardized Relationships among Variables

Source: own study.

In our model, the psychological factors that were hypothesized to be related to intrinsic motivation were differentially significant. It was hypothesized that sport enjoyment would be positively associated with the intrinsic motivation score; this hypothesis was confirmed $(\beta=.28, \mathrm{p}<.01)$. On the other hand, the hypothesis that the social self-efficacy score would be positively associated with the intrinsic motivation score was not confirmed $(\beta=-.08, \mathrm{p}>.05)$, although a positive correlation among the variables was present 
(see Table 1). It was also hypothesized that training-and-instruction coaching behavior would be positively linked with the intrinsic motivation score, and data did indeed support our hypothesis $(\beta=.21, \mathrm{p}<.05)$. Furthermore, data did not support our hypothesis that the democratic-style coaching behavior would be positively linked with the intrinsic motivation score $(\beta=-.12, \mathrm{p}>.05)$. Then, autocratic-style coaching behavior was also found to be unrelated to intrinsic motivation $(\beta=-.05, \mathrm{p}>.05)$. As expected, a positive association was discovered between social-support coaching behavior $(\beta=.17, \mathrm{p}<.05)$ and intrinsic motivation. Subsequently, it was hypothesized that the positive-feedback coaching behavior would be positively linked with the intrinsic motivation score; however, the data did not support our hypothesis $(\beta=.08, \mathrm{p}>.05)$.

Based on these results, two mediation analyses were conducted, considering social-support coaching behavior (model 1) and a training-and-instruction coaching behavior (model 2) as independent variables, intrinsic motivation as dependent variable, and sport enjoyment as mediator.

Relation between social-support coaching behavior and intrinsic motivation considering the mediation of sport enjoyment. Considering model 1 , the analysis did not reveal a significant relation between the predictor (social-support coaching behavior) and mediator (sport enjoyment) $(\beta==.18, p>.05$ ), thus the required conditions for a mediation were not found.

Relation between training-and-instruction coaching behavior and intrinsic motivation considering the mediation of sport enjoyment. Considering model 2, the analysis revealed a significant relation between the predictor (training-and-instruction coaching behavior) and the mediator (sport enjoyment) $(\beta=.29, \mathrm{p}<.001)$. The coefficient for the regression association between training and instruction and intrinsic motivation was also significant $(\beta==.41, \mathrm{p}<.001)$. A decrease was observed in the coefficient of this regression $(\beta=.323, p<.001)$ when the mediator, sport enjoyment, was included in the regression model ( $\beta==.318, \mathrm{p}<.01$ ). The inclusion of the mediator contributed to an increase of $10 \%$ in the explained variance $\left(R^{2}=.10\right)$. Finally, the Sobel test for mediation that determines if the coefficient decrease is significant or reliable indicated that the mediation model was partially mediated $(z=2.47, \mathrm{p}<.01)$.

Table 2. Standardized Regression Coefficients of Intrinsic Motivation (Outcome), Training, and Instruction Coaching Leadership Style (Predictor), Enjoyment (Mediator)

\begin{tabular}{llllll}
\hline & $\mathrm{n}=127$ & \multicolumn{3}{c}{ Intrinsic Motivation } & \\
& & $\mathrm{B}$ & $\mathrm{SE}$ & $\mathrm{B}$ & $\mathrm{p}$ \\
\hline Step 1 & Training-and-instruction coaching leadership style & .35 & .08 & .41 & $<.001$ \\
Step 2 & Training-and-instruction coaching leadership style & .28 & .07 & .32 & $<.001$ \\
& Enjoyment & .57 & .16 & .32 & $<.001$ \\
\hline
\end{tabular}

Note: Significant relation between the predictor (training-and-instruction coaching behavior) and the outcome (intrinsic motivation). Significant decrease in the coefficient of this regression once the mediator (sport enjoyment) is included in the regression model indicating a partial mediation. Sobel Test: $z=2.47, p=.01$.

Source: own study.

\section{Conclusion}

This study aimed to determine the correlates of intrinsic motivation in Italian early adolescent female athletes. These associations were investigated by testing a model in which it is assumed that intrinsic motivation could be related to both psychological and sociorelational factors. Subsequently, this study clarified the dynamics between intrinsic motivation and the psychosocial-relational factors significantly associated with it, hypothesizing that the association among social-relational factors (training and instruction, social support) and intrinsic motivation was mediated by psychological factors (enjoyment).

First, our findings highlighted that both psychological and sociorelational factors were related to intrinsic motivation. Regarding psychological factors, sport enjoyment was associated with females' intrinsic motivation. According to the SDT, although overall prior work has considered sport enjoyment as a measure 
or an outcome of intrinsic motivation, in the current study sport enjoyment was assumed to be a factor that enhances intrinsic motivation. Therefore, this study provides an original consideration of enjoyment as an antecedent of intrinsic motivation and a possible effective strategy for sustaining intrinsic motivation among early adolescent Italian females. Considering social-relational factors, two coaching behaviors were significantly associated with intrinsic motivation: training-and-instruction and social support coaching leadership styles. These findings suggested that during early adolescence, intrinsic motivation was related to a coach who emphasizes both the technical sport aspects and the social and affective aspects in his or her relationship with the athlete. It is clear from these findings that, for early adolescent females, having a coach who teaches practices and techniques to enhance sports (Amorose \& Horn, 2000) and with whom it is also possible to build a close and supportive relationship may be an indirect way to sustain their sport activity involvement (Mahoney, Larson, Eccles, Lord, 2005). This aspect can be especially important for early adolescent females who are more likely than males to desire support in their relationship (for a review, see Rose \& Rudolph, 2006). The findings about the positive role of training-and-instruction and social support coaching behavior clarify the existing inconsistent literature about their contribution to intrinsic motivation (see Amorose \& Horn, 2000, 2001; Hollembeak \& Amorose, 2005). No evidence was found to support the idea that perceived social self-efficacy was related to intrinsic motivation. The contribution of perceived competence on intrinsic motivation has been well documented in research, but the role of social self-efficacy has been investigated to a lesser extent (Deci \& Ryan, 1985, 1991; Ferrer-Caja \& Weiss, 2000). The social context of sport is salient to participants' motivation and participants' reports of social reasons for engaging in physical activities, including affiliation and being part of a team (Allen, 2003). Sport clearly has meaning to participants because it provides opportunities for interpersonal interaction and the development of social bonds with others, especially during early adolescence. Despite the salience of numerous social aspects of sport to participants, in the present study a significant association was not found. One possible explanation for this absence of an association between the perception of social competence and intrinsic motivation is that during early adolescence, friendships and females' perception of their social competence are not stable and are subject to continuous change and development (Martin \& Fabes, 2000). Nonetheless, as social selfefficacy is a specific construct related to the general self-concept and that peer experience is motivationally salient for youths, further research should deepen the association between social self-efficacy and intrinsic motivation. However, considering these findings, the present research offered significant contributions to earlier work on intrinsic motivation and self-determination theory. To our knowledge, the study takes into account for the first time the simultaneous role of some psychological factors and a variety of coaching behaviors on the level of intrinsic motivation. Second, it reflects on some less-explored psychological aspects, such as social self-efficacy and enjoyment, and all the coaching style behavior of the Chelledurai model (1980) in order to clarify which is significantly associated with intrinsic motivation. The majority of the previous studies were instead concentrated on investigating the contribution of one specific coaching behavior (e.g., Vallerand \& Reid, 1984; Whitehead \& Corbin, 1991). Moreover, this study suggests an alternative role of sport enjoyment as an antecedent of intrinsic motivation. The interest was specifically devoted to the Italian early adolescent female athletes, a group at risk of early sport dropout.

The mediation process did not provide evidence for social support coaching behavior because it was not associated with sport enjoyment. It is likely that the sport enjoyment of females who are beginning competitive sport practice does not depend on the closeness to their coaches. The role of the coaches' social support in psychological factors is controversial: A positive relation was found by Amorose and AndersonButcher (2007), while other studies disconfirmed this relation (Hollembeak \& Amorose, 2005). Future research should explore this relationship more closely by examining, for example, which type of support can contribute to female athletes' sport enjoyment. Instead, a training-and-instruction coaching leadership style was positively associated with sport enjoyment. As SDT states, the contribution of the coach is also important in providing enjoyment in sport practice. Sport enjoyment is not the only aspect that accounts for athletes' emotional personal attitudes toward sport, but it is also an aspect strictly linked to and improved by coaches' behaviors and actions. According to our results, having a coach who emphasized technical and 
sport instruction contributed to providing female athletes with enjoyable sport experiences. Moreover, this sport enjoyment contributed to their intrinsic motivation toward sport activity.

In sum, also considering the second objective, the present study extended previous research on intrinsic motivation and SDT in various ways. The study clarified the dynamics between coaching behavior and intrinsic motivation by testing whether this association was mediated by enjoyment. According to SDT and Vallerand's motivational sequence model, a few notable studies have tested the mediation effect of some psychological factors (e.g., perceived competence, autonomy) in the above-mentioned relationship, but they have completely ignored the role of enjoyment. Although the SDT-based model proposed by Vallerand $(1997,2007)$ has not considered sport enjoyment as an athlete's fundamental need, our findings suggested that to fully understand the associations between coaching behavior (e.g., training and instruction) and intrinsic motivation, sport enjoyment needs to be examined. Sport enjoyment represents not only an intrinsic motivation outcome as SDT states, but it represents a factor able to sustain athletes' intrinsic motivation. The level of enjoyment that athletes experiment in their sport activity may improve their intrinsic motivation. So, the study extended the SDT-Vallerand-based model to other psychological needs that need to be satisfied. Future research should confirm the enjoyment mediation effect between coaching behavior and intrinsic motivation. In keeping with the results, some innovative and valid suggestions should be noted for coaches and leaders. First, coaches who are technically instructed and prepared are able to improve athletes' sport enjoyment and, consequently, their intrinsic motivation. Second, also in an agonistic sport context, sport enjoyment is fundamental and necessary in order to maintain the desire to take part in sport activities. This is especially important considering the stage of early adolescence in which the risk of dropout is greater than in any other stage of development, especially among females. Finally, although supportive coaching behavior was not related to athletes' enjoyment, it is necessary to underline its direct contribution toward athletes' intrinsic motivation. Thus, in order to sustain intrinsic behavior among young athletes, close and supportive coaching behaviors are required.

The current study had certain limitations. First, the design of the present study was cross-sectional; therefore, all relationships are correlational and nondirectional. Future research testing this temporal process and examining how these factors change over time would provide more precise information about these variables and their causal relationships. Second, because the participants were early adolescent females, external validity is limited. Third, only youths' self-reported ratings were used. Utilizing a combination of parents' and coaches' ratings could have offered a more practical assessment of the social variables. Finally, in the present study, it was not possible to study, according to the 4-stage causal sequence proposed by Vallerand's model, the consequences of intrinsic motivation. As some studies have shown, self-determined motivation (e.g., intrinsic motivation) leads to some positive outcomes (e.g., low level of dropout) in different contexts (i.e., school, sport setting) (Sarrazin et al., 2002; Vallerand, 1997). Future studies testing this causal sequence should provide some information about, for example, the protective role of intrinsic motivation toward the Italian early adolescent females' sport dropout.

Despite these limitations, given the positive role sport can play during the developmental age in terms of a physical and mental healthy lifestyle (Mahoney, Larson, \& Eccles, 2005), this study provided some practical implications that could be useful in order to maintain the high sport participation and sport engagement of Italian early adolescent females over time.

\section{REFERENCES}

Allen, J.B. (2003). Social motivation in youth sport. Journal of Sport and Exercise Psychology, 25, 551-567.

Amorose, A.J., Anderson-Butcher, D. (2007). Autonomy-supportive coaching and self-determined motivation in high school and college athletes: A test of self-determination theory. Psychology of Sport and Exercise, 8(5), 654-670.

Amorose, A. J., Horn, T. S. (2000). Intrinsic motivation: relationships with collegiate athletes' gender, scholarship status, and perceptions of their coaches' behavior. Journal of Sport and Exercise Psychology, 22, 63-84.

Amorose, A.J., Horn, T.S. (2001). Pre- to post-season changes in the intrinsic motivation of first year college athletes: Relationships with coaching behavior and scholarship status. Journal of Applied Sport Psychology, 13, 355-373. 
Bandura, A. (Ed.). (1997). Self-efficacy: The exercise of control. New York, NY: Freeman.

Baron, R., Kenny, D.A. (1986). The moderator-mediator variable distinction in social psychological research: conceptual, strategic and statistical considerations. Journal of Personal Social Psychology, 51, 1173-82.

Caprara, G.V. (Ed.). (2001). La valutazione dell'autoefficacia/The assessment of self-efficacy/. Trento, IT: Erickson.

Carraro, A., Young, M.C., Robazza, C. (2008). A contribution to the validation of the physical activity enjoyment scale in an Italian sample. Journal of Social Behavior and Personality, 36(7), 911-918.

Chelledurai, P., Saleh, S.D. (1980). Dimensions of leader behavior in sports: Development of a leadership scale. Journal of Sport Psychology, 2(1), 34-45.

Deci, E.L., Ryan, R.M. (Eds.). (1985). Intrinsic motivation and self-determination in human behavior. New York, NY: Plenum.

Deci, E.L., Ryan, R.M. (1991). A motivational approach to self: Integration in personality. In R. Deinstbier (Ed.), Nebraska symposium on motivation: Vol. 38. Perspectives on motivation (pp. 237-288). Lincoln: University of Nebraska Press.

Duda, J.L. (2007). Motivation in a sport setting: A goal perspective approach. In D. Smith, M. Bar-Eli (Eds.), Essential readings in sport and exercise psychology (pp. 78-102). USA: Human Kinetics.

Duncan, S.C. (1993). The role of cognitive appraisal and friendship provisions in adolescents' affect and motivation toward activity in physical education. Research Quarterly for Exercise and Sport, 64, 314-323.

Ferrer-Caja, E., Weiss, M.R. (2000). Predictors of intrinsic motivation among adolescent students in physical education. Research Quarterly for Exercise and Sport, 71(3), 267-279.

Fraser-Thomas, J.L., Cote, J., Deakin, J. (2005). Youth sport programs: An avenue to foster positive youth development. Physical Education and Sport Pedagogy, 10, 19-40.

Hollembeak, J., Amorose, A.J. (2005). Perceived coaching behaviors and college athletes' intrinsic motivation: A test of self-determination theory. Journal of Applied Sport Psychology, 17, 20-36.

Kendzierski, D., DeCarlo, K.J. (1991). Physical activity enjoyment scale: Two validation studies. Journal of Sport \& Exercise Psychology, 13(1), 50-64.

Klint, K. A., \& Weiss, M. R. (1987). Perceived competence and motives for participating in youth sports: A test of Harter's competence motivation theory. Journal of Sport Psychology, 9, 55-65.

Mahoney, J.L., Larson, R.W., Eccles, J.S. (Eds.). (2005). Organized activities as contexts of development: Extracurricular activities, after-school and community programs. Mahwah, NJ: Lawrence Erlbaum \& Associates.

Mahoney, J.L., Larson, R. W., Eccles, J. S., \& Lord, H. (2005). Organized activities as developmental contexts for children and adolescents. In J. Mahoney, R. Larson \& J. Eccles (Eds.), Organized activities as contexts of development (pp. 3-22). Mahwah, NJ: Lawrence Erlbaum Associates.

Martin, C. L., Fabes, R. A. (2001). The stability and consequences of young children's same-sex peer interactions. Developmental Psychology, 37(3), 431-446.

McDonough, M. H., Crocker, P. R. E. (2005). Sport participation motivation in young adolescent girls: The role of friendship quality and self-concept. Research Quarterly for Exercise and Sport, 76, 456-467.

National Institute of Statistics [Istituto Nazionale di Statistica]. (2012). Italy in figures 2012. Retrieved from http://www.istat.it/it/files/2012/06/italiaincifre2012.pdf

National Italian Olympic Committee [CONI]. (2011). Sport in Italy 2011. Retrieved from http://www.olympic.org/italy

Ntoumanis, N. (2001). A self-determination approach to the understanding of motivation in physical education. British Journal of Educational Psychology, 71, 225-242.

Ntoumanis, N. (2005). A prospective study of participation in optional school physical education based on selfdetermination theory. Journal of Educational Psychology, 97, 444-453.

Pelletier, L.G., Fortier, M.S., Vallerand, R.J., Briere, N.M. (2001). Associations among perceived autonomy support, forms of self-regulation, and persistence: A prospective study. Motivation and Emotion, 25, 279-306.

Pelletier, L.G., Fortier, M.S., Vallerand, R.J., Tuson, K.M., Briere, N.M., Blais, M.R. (1995). Toward a new measure of intrinsic motivation, extrinsic motivation, and amotivation in sports: The Sports Motivation Scale (SMS). Journal of Sport and Exercise Psychology, 17, 35-53.

Pelletier, L.G., Vallerand, R.J., Sarrazin, P. (2007). The revised six factor Sport Motivation Scale (Mallett, Kawabata, Newcombe, Otero-Forero, Jackson, 2007): Something old, something new, and something borrowed. Psychology of Sport and Exercise, 8, 615-621.

Reinboth, M., Duda, J.L. (2006). Perceived motivational climate, need satisfaction and indices of well-being in team sports: A longitudinal perspective. Psychology of Sport and Exercise, 7, 269-286. 
Rose, A.J., Rudolph, K.D. (2006). A review of sex differences in peer relationship processes: Potential trade-offs for the emotional and behavioral development of girls and boys. Psychological Bulletin, 132, 98-131.

Ryan, R. M., Deci, E. L. (2000). Intrinsic and extrinsic motivations: Classic definitions and new directions. Contemporary Educational Psychology, 25, 54-67.

Sallis, J.P., Prochaska, J.J., Taylor W.C. (2000). A review of correlates of physical activity of children and adolescents. Medicine Science Sports, 32(5), 963-75.

Sarrazin, P., Vallerand, R.J., Guillet, E., Pelletier, L.G., Cury, F. (2002). Motivation and dropout in female handballers: A 21-month prospective study. European Journal of Social Psychology, 57, 749-761.

Ullrich-French, S., Smith, A.L. (2009). Social and motivational predictors of continued youth sport participation. Psychology of Sport and Exercise, 10(1), 87-95.

Vallerand, R. J. (1997). Toward a hierarchical model of intrinsic and extrinsic motivation. In M. Zanna (Ed.), Advances in experimental social psychology (pp. 271-360). New York, NY: Academic Press.

Vallerand, R.J. (2007). Intrinsic and extrinsic motivation in sport and physical activity. A review and a look at the future. In G.C. Tenenbaum, R. Eklund (Eds.), Handbook of sport psychology ( ${ }^{\text {rd }}$ ed.) (pp. 59-83). New York, NY: John Wiley.

Vallerand, R.J., Reid, G. (1984). On the casual effects of perceived competence on intrinsic motivation: A test of cognitive evaluation theory. Journal of Sport Psychology, 6, 94-102.

Vescio, J., Wilde, K., Crosswhite, J.J. (2005). Profiling sport role models to enhance initiatives for adolescent girls in physical education and sport. European Physical Education Review, 11, 153-170.

Weiss, M.R., Kimmel, L.A., Smith, A.L. (2001). Determinants of sport commitment among junior tennis players: Enjoyment as a mediating variable. Pediatric Exercise Science, 13, 131-144.

Weiss, M. R., Smith, A. L., Theehoom, M. (1996). "That's what friends are for": Children and teenager perceptions of peer relationships in the sport domain. Journal of Sport and Exercise Psychology, 18, 347-379.

Whitehead, J., Corbin, C. (1991). Youth fitness testing: The effect of percentile-based evaluative feedback on intrinsic motivation. Research Quarterly for Exercise and Sport, 62, 225-231.

Wylleman, P. (2000). Interpersonal relationships in sport: Uncharted territory in sport psychology research. International Journal of Sport Psychology, 31, 555-572.

AUTHOR'S ADDRESS:

Gulia Zucchetti

Laboratory of Developmental Psychology

Department of Psychology

University of Torino

Via Verdi 1010124 Torino

Italy

Email: giulia.zucchetti@unito.it 